\title{
Preventing sexual abusers of children from reoffending: systematic review of medical and psychological interventions
}

\author{
(c) $(1) \circledast$ OP OPEN ACCESS
}

\author{
Niklas Långström professor ${ }^{12}$, Pia Enebrink clinical psychologist, researcher ${ }^{3}$, Eva-Marie Laurén \\ senior forensic psychiatrist ${ }^{4}$, Jonas Lindblom researcher ${ }^{56}$, Sophie Werkö researcher ${ }^{56}$, R Karl \\ Hanson senior research scientist ${ }^{7}$
}

${ }^{1}$ Department of Medical Epidemiology and Biostatistics, Karolinska Institutet, Box 281, SE-171 77 Stockholm, Sweden; ${ }^{2}$ Swedish Prison and Probation Administration, Norrköping, Sweden; ${ }^{3}$ Department of Clinical Neurosciences, Division of Psychology, Karolinska Institutet, Box 281, SE-171 77 Stockholm, Sweden; ${ }^{4}$ Stockholm County Council, Stockholm, Sweden; ${ }^{5}$ Swedish Council on Health Technology Assessment (SBU), Stockholm, Sweden; ${ }^{6}$ LIME, Karolinska Institutet, SE-106 91, Stockholm, Sweden; ${ }^{7}$ Public Safety Canada, Ottawa, ON, Canada

\begin{abstract}
Objective To evaluate the effectiveness of current medical and psychological interventions for individuals at risk of sexually abusing children, both in known abusers and those at risk of abusing.

Design Systematic review of interventions designed to prevent reoffending among known abusers and prevention for individuals at risk of sexually abusing children. Randomised controlled trials and prospective observational studies were eligible. Primary outcomes were arrests, convictions, breaches of conditions, and self reported sexual abuse of children after one year or more.

Results After review of 1447 abstracts, we retrieved 167 full text studies, and finally included eight studies with low to moderate risk of bias. We found weak evidence for interventions aimed at reducing reoffending in identified sexual abusers of children. For adults, evidence from five trials was insufficient regarding both benefits and risks with psychological treatment and pharmacotherapy. For adolescents, limited evidence from one trial suggested that multisystemic therapy prevented reoffence (relative risk $0.18,95 \%$ confidence interval 0.04 to 0.73 ); lack of adequate research prevented conclusions about effects of other treatments. Evidence was also inadequate regarding effectiveness of treatment for children with sexual behavioural problems in the one trial identified. Finally, we found no eligible research on preventive methods for adults and adolescents who had not sexually abused children but were at higher risk of doing so (such as those with paedophilic sexual preference).

Conclusion There are major weaknesses in the scientific evidence, particularly regarding adult men, the main category of sexual abusers
\end{abstract}

of children. Better coordinated and funded high quality studies including several countries are urgently needed. Until conclusive evidence is available, realistic clinical strategies might involve reduction of specific risk factors for sex crimes, such as sexual preoccupation, in abusers at risk of reoffending.

\section{Introduction}

Sexual abuse of children is a global problem, and systematic reviews suggest that $18-20 \%$ of women and $7-8 \%$ of men in the general population report being abused before the age of $18 .^{12}$ Rates have not differed substantially in recent decades but might vary across regions. ${ }^{2}$

Although most research designs are suboptimal for robust conclusions regarding causal effects, sexual violence is undoubtedly associated with a lasting impact on the health of children who have been abused. ${ }^{3-6}$ Putative consequences include risky sexual behaviour, chronic pain syndromes, anxiety, and depressive disorders including post-traumatic stress disorder, ${ }^{7-9}$ substance misuse, ${ }^{7-10}$ suicide attempts, ${ }^{8}$ and sexually aggressive behaviour. ${ }^{11-13}$ Identified associations are generally small to moderate in size and are influenced by sample origin and size.

The high prevalence and adverse consequences of sexual abuse of children warrant increased investment in development of preventive and therapeutic strategies. ${ }^{14-16}$ Such efforts should directly deal with children, their caregivers, and their environments to prevent potential abuse and effectively manage 
cases of abuse that have already occurred. Interventions for individuals at risk of sexual abusing children could prevent more children from being abused.

Society's response to people who sexually abuse children has focused largely on punishment and deterrence through the criminal justice system. Offenders, however, are often directed to mental health professionals for treatment of disorders related to the offence (such as sexual compulsivity and paedophilia). Consequently, the availability of evidence based treatment for this population would be of considerable interest to medical practitioners.

Several systematic reviews have evaluated the effects of psychological and pharmacological treatments aimed at reducing reoffence in adult sexual abusers of other adults or children. ${ }^{17-22}$ Although the weighted support is equivocal regarding treatment effects, a recent systematic review ${ }^{23}$ suggested that interventions for sexual offenders in general are more successful if they follow the risk, needs, and responsivity principles of effective correctional treatment. ${ }^{24}$ These principles state that human service interventions are most likely to reduce reoffending when the dose and intensity of the treatment is consummate with the offender's risk for reoffence (risk principle), when the treatment targets characteristics associated with risk of reoffence (that is, criminogenic needs, need principle), and when the treatment is delivered in a manner consistent with the offender's cultural background and learning style (responsivity principle). No previous research, however, has specifically examined the applicability of these principles to the treatment of sexual abusers of children.

Though the humanitarian and economic costs of child sexual abuse are extensive, remarkably little interest has been directed at identifying which medical and psychological interventions actually prevent abuse in individuals at risk of abusing and known abusers. We assessed the effects of such preventive methods for identified perpetrators or those at risk of committing sexual offences against children. Despite extensive searches, we could not find any studies concerning interventions for non-offenders at risk of starting to sexual abuse children. All included studies therefore examined interventions for individuals already known to have committed a sexual offence against a child.

\section{Methods}

\section{Design and search strategy}

We conducted a systematic review of randomised controlled trials and prospective controlled observational studies, identifying studies through searches of PubMed (NLM), PsycInfo (EBSCO), National Criminal Justice Reference Service Abstracts (EBSCO), Cochrane Library, and Campbell Library up to June 2013. Appendix 1 lists the search criteria.

Additionally, we used reference lists, books, and websites to identify further studies, including grey literature.

Using standard eligibility criteria tailored for this study (appendix 1), a PhD level clinical psychologist (PE) and a professor and child psychiatrist (NL) with clinical and research expertise concerning sexual abuse and sexual offending reviewed studies for inclusion. These reviewers worked independently, and, if either reviewer considered a study potentially eligible from information in the abstract only, the full text was obtained. Both reviewers read the full text reports and achieved consensus for eligibility. Eligible studies advanced to the next level of review, also conducted by two $\mathrm{PhD}$ level researchers (JL, SW) at the Swedish Council on Health Technology Assessment
(SBU). Both had expertise in research synthesis of medical procedures but no particular background in sexual abuse research.

The second level of review involved calculation of effect sizes (risk ratios) and estimated bias. If the SBU reviewers had concerns about the eligibility of a particular study, the study was referred back to the two content experts, with a final decision based on the consensus of all four reviewers. The conclusions were based on a synthesis of the research evidence by using the Grading of Recommendations Assessment, Development and Evaluation (GRADE) approach. ${ }^{25}{ }^{26}$ We did not calculate inter-rater reliability. Disagreements concerning ratings of bias were also resolved through discussion among all four reviewers. Members of the project group were not allowed to assess their own articles. Further details concerning the method are available in appendix 1 and 2 and from SBU. ${ }^{27}$

\section{Study eligibility}

We included all randomised controlled trials and prospective controlled observational studies (cohort studies, follow-up studies, or case-control studies with prospectively collected data) of adult or adolescent perpetrators or potential perpetrators of child sexual abuse and studies of children with sexual behaviour problems. Interventions could be pharmacological (such as antiandrogenic drugs), psychological, or psychoeducational. No time limits were imposed concerning date of publication; outdated treatments that were only of historical interest, however, were excluded (such as aversion therapy). Control groups underwent treatment as usual or, for some reason, received no treatment (reason determined study inclusion; we excluded studies with control groups consisting primarily of those who dropped out or refused treatment).

Eligible outcomes were conviction on charges of sexual offences against children (including possession of child pornography), arrest by police on suspicion of the same offences, breaches of conditions while serving a sentence for sexual offending, and self reported sexual abuse against children. We included studies written in English or any of the Scandinavian languages. The treatment and the comparison group had to include at least 20 people each, and the follow-up period had to be at least a year. We excluded studies with irrelevant or obviously biased comparison groups (such as treatment dropouts).

\section{Determination of bias and research synthesis}

Bias was determined with a structured professional judgment procedure that is standard practice at SBU and similar to those used in other health technology assessment reviews (see appendix 3). Synthesis of the research evidence was based on the GRADE approach (see appendix 1) ${ }^{25}{ }^{26} \mathrm{We}$ considered studies with adequate randomisation process, that included at least 20 individuals per group, and that were balanced in terms of potentially confounding factors as having moderate risk of bias (see appendix 1). Consistent with SBU procedures, only studies with low or moderate risk of bias were considered in the synthesis. Studies in which known risk factors differed between groups and were not handled in analyses were deemed to have a high risk of bias and were excluded (see appendix 1).

\section{Results}

We reviewed 1447 abstracts, 167 of which were deemed potentially eligible by at least one of the initial reviewers. Based on full text review, 145 of these studies were considered ineligible, primarily because they were reviews or commentaries 
with no original data $(n=58)$, no control group $(n=31)$, or the outcomes were reported only for mixed groups of sexual offenders and not specifically for sexual offenders against children ( $\mathrm{n}=18$ ) (figure $\Downarrow$ ). Of the 22 remaining studies, 14 were rated as having a high risk of bias and were not considered further; leaving eight studies with low or moderate risk of bias (table 1). $\Downarrow$

Table 2 provides brief descriptions of examined treatments. $\Downarrow$ The treatments were usually manual based group therapy, followed cognitive behavioural therapy principles, and aimed at lowering the impact of risk factors driving sexual offending, such as changing distorted views on sexuality and reducing sexual preoccupation and easily triggered aggressiveness. Manual based group therapies specify an ordered sequence of content to be covered in the group sessions and directions for maintaining a productive therapeutic climate. We did not include any studies of testosterone inhibiting drugs because all identified controlled primary studies had high overall risk of bias.

Table 3 summarises the effects of interventions. $\Downarrow$ With adults who sexually abused children (five studies with low or moderate risk of bias: one randomised controlled trial with moderate risk offenders ${ }^{28}$ three observational studies with lower risk offenders, ${ }^{29-31}$ and one observational study with higher risk offenders ${ }^{32}$ ), the scientific evidence was insufficient to determine if cognitive behavioural therapy with relapse prevention reduces sexual reoffending. No scientific evidence was available to determine if psychological interventions other than cognitive behavioural therapy or if pharmacological treatment reduce sexual reoffending among adult child abusers (no studies). Neither did we find evidence to determine if psychological or pharmacological methods of treatment could prevent sexual offending among adults who have not sexually abused a child but are at risk of doing so (no studies).

For adolescent sexual offenders (who primarily target other children or adolescents), limited evidence (one randomised controlled trial with moderate study quality ${ }^{33}$ ) suggested that multisystemic therapy could be effective in preventing sexual reoffending among moderate risk adolescent sex offenders (relative risk $0.18,95 \%$ confidence interval 0.04 to 0.73 ). The scientific evidence was insufficient (one observational study with moderate quality ${ }^{34}$ ) to determine if cognitive behavioural therapy is effective at preventing sexual reoffending among moderate risk adolescent sex offenders (table $3 \Downarrow$ ). No evidence was available to determine the effect of cognitive behavioural therapy on sexual reoffending among adolescent sex offenders with low or high risk of reoffending. Neither did we find scientific evidence to determine the effectiveness of other methods (psychological or pharmacological) aimed at preventing sexual reoffending in adolescent sex offenders. Finally, evidence was lacking to determine the effectiveness of methods aimed at preventing sexual offending in adolescents who have not sexually abused a child but are at risk of doing so.

For children under the age of 13 with sexual behaviour problems towards other children, we found insufficient evidence (one high quality randomised controlled trial ${ }^{35}$ ) to determine if cognitive behavioural therapy combined with parental support was more effective than standard treatment in preventing sexual offending. No scientific evidence was available to determine the effectiveness of other preventive interventions for children with sexual behaviour problems.

Information concerning adverse outcomes of treatment (other than criminal reoffending) was not available.

\section{Discussion}

Despite severe consequences for victims and society, this systematic review identified remarkably little research of acceptable quality on individual-level prevention of child sexual abuse. We found only three randomised controlled trials: one in adults, ${ }^{28}$ one in adolescents, ${ }^{33}$ and one in children with sexual behaviour problems towards other children. ${ }^{35}$ The remaining five primary studies were all observational. ${ }^{29-32}{ }^{34}$ Consequently, there is the risk that imbalance could arise between treatment and control groups if participation in the intervention was based on risk relevant factors, such as participant's motivation for treatment.

Public debate on sexual offences against children usually centres on how to punish the perpetrator. The public commonly demands that sexual abusers of children receive interventions that can be administered only by physicians, such as chemical castration. ${ }^{36} 37$ From the medical perspective, however, the primary aim is to identify and treat disorders associated with the risk of someone sexually abusing children.

Although more than $70 \%$ of all sexual abusers of children are adult men, we found only one randomised controlled trial of acceptable study quality examining a plausible treatment for adult perpetrators, and it found no effect of an intervention combining cognitive behavioural therapy and relapse prevention treatment. ${ }^{28}$ Yet, despite being the largest primary study included, it was still too small to statistically secure potential treatment effects and should not be interpreted as evidence that cognitive behavioural therapy and relapse prevention is without effects. The four included observational studies also had limitations that ruled out reliable conclusions about cognitive behavioural therapy. ${ }^{29-32}$ Additionally, no other psychological or pharmacological interventions were supported by studies with sufficiently low risk of bias for inclusion.

The lack of credible studies of antiandrogen drugs is particularly striking given the prominence of "chemical castration" in public debates concerning the treatment of known perpetrators. ${ }^{37}$ The evidence on potential treatment effects was somewhat better for adolescents than adults. Although the included randomised controlled trial was small, it provided limited scientific evidence that multisystemic therapy - a community based programme based on social learning, social ecological theory, and systematic family therapy-reduces sexual reoffending among sexually abusive adolescents. One limitation is that the effectiveness of this therapy seems to be reduced when it is implemented by non-researchers outside the settings in which it was originally developed. ${ }^{38} 39$

One single randomised controlled trial that met our inclusion criteria examined children with sexual behavioural problems. Carpentier and colleagues randomised such children to either cognitive behavioural therapy or a control group who received group based play therapy. ${ }^{35}$ Both interventions were combined with parental support. Albeit otherwise well executed, this study was also underpowered and the results not significant. Hence, the scientific evidence is insufficient to determine if cognitive behavioural therapy or any other intervention is effective in preventing future sexual offences in children with sexual behavioural problems. Further, Carpentier and colleagues found that the risk for sexually abusive behaviour over a 10 year follow-up was also low among the untreated children (10\% of controls reportedly committed a sexual offence compared with $2 \%$ of those treated with cognitive behavioural therapy).

Consequently, if a child is overly perceived as threatening and as a future sex offender, this could lead to unjustified stigmatisation and could negatively affect the child's 
development. Hence, risk should be balanced against the relatively low base rate of future sexually abusive behaviour among children with sexual behavioural problems. If these children are subjected to excessively intense or inappropriate therapy, this could increase the risk for future antisocial behaviour. An important evidence based alternative to treating such children would be to provide structured training or education for the primary caregivers to improve their parenting skills, as has been successful with parents of children with conduct disorder. ${ }^{40}$

The remarkable lack of quality research studies in sexual abusers of children can be partially attributed to the public condemnation of sexual offenders that views punishment as a sufficient response to their transgressions. The lack of randomised controlled trials can also be attributed to the logistic, legal, and ethical challenges faced by those wanting to conduct high quality research on sensitive social issues. Currently, many correctional systems require that sexual abusers of children receive treatment as a condition of release or community supervision. Withholding treatment could interfere with the expected progression of offenders through correctional systems and would introduce unknown risks to public safety by deliberately releasing people with sexually deviancy who did not receive what is considered to be best current treatment.

Professional opinion, however, is no substitute for evidence. When we consider the overall unimpressive treatment effects presented here, it should be acknowledged that psychological interventions, like pharmacotherapy, might also have negative side effects. Under certain circumstances, with some people and some interventions, treatment could increase the risk of sexual reoffending. ${ }^{41}$ For instance, prolonged or intense interventions for offenders at low risk of relapse, or grouping low risk offenders with those at high risk for reoffending, could result in adverse outcomes.

We also searched for studies evaluating interventions aimed at individuals at higher risk of sexually abusing children but who had not committed any such offence. Unfortunately, we found no such completed studies and only one study in progress. ${ }^{42}$

Without specific guidelines for treating individuals at risk, the most ethically defensible position would be to assess the presence of treatable risk factors for sexual abuse of children, including concurrent psychiatric disorder, and offer individualised treatment. Research on sex offenders in general (that is, not only those who sexually abuse children) suggests that treatment is more successful if it adheres to the risk, needs, and responsivity (RNR) principles for effective treatment of offenders. ${ }^{23}$ According to these principles, offenders with high or moderate risk of reoffending should be prioritised for treatment and offered longer and more intensive interventions. Offenders with a low risk of reoffending should receive less intensive and shorter interventions and not be grouped with higher risk offenders. Moreover, treatment should target causal risk factors driving sex crimes, adhere to the principles of social learning theory, and be adapted to the learning style of the individual. Although no specific research affirms that these principles also apply to sexual abusers of children, it is usually perceived as unethical to deny treatment, hence reflecting a fundamental dilemma. We suggest that while we wait for better evidence from research, treatment of offenders who have sexually abused children should be based on the risk, needs, and responsivity principles and the effects carefully documented.

\section{Strengths and limitations}

This review is a comprehensive synthesis of current research examining interventions for individuals at risk of sexually abusing children. The methods used for research synthesis are widely accepted, allowing for direct comparison with the quality of evidence available for other medical interventions.

In terms of limitations, we used only one procedure to rate bias and summarise the evidence. Different methods of rating study quality can lead researchers to different conclusions. ${ }^{43}$

Furthermore, we considered only research in English and the Scandinavian languages. It is unlikely, however, that we failed to include higher quality studies. A recent Cochrane review examining a broader population (sexual offenders) and broader outcome criteria (any clinically relevant measure) similarly concluded that there was not enough research. ${ }^{44}$

\section{Conclusions and future directions}

Based on the meagre results from our extensive systematic review, we conclude that there is an urgent need for well designed and well executed trials of treatment for adults who commit sexual offences against children. One challenge for evaluation research is that the observed rate of reoffence for sexual abusers of children is low (for example, $12.7 \%$ after four to five years, $n=9603) .{ }^{45}$ With yearly hazard rates of less than $3 \%$, studies need large samples and long follow-up periods. As most states and countries are too small to overcome these intrinsic problems with evaluation on their own, larger multinational randomised controlled trials should be conducted. In 2007, the Council of Europe adopted the Convention on the Protection of Children against Sexual Exploitation and Sexual Abuse. ${ }^{46}$ As of 3 July 2013, all but one of the member states of the Council of Europe had signed the convention and it had been ratified by 27 countries. This convention creates an obligation to offer effective treatment to sexual abusers of children, individuals at higher risk of committing such offences, and children with sexual behaviour problems. Furthermore, the convention implies that those joining should also assess the effects of initiated programmes. Countries joining the convention should therefore share a common interest in developing effective methods to prevent sexual offences against children and support research to determine the effectiveness of implemented programmes. We suggest that these countries initiate collaborative research to bridge the major knowledge gaps.

The introduction of intervention programmes in jurisdictions previously lacking established programmes provides a unique opportunity for strong research designs. When the capacity for treatment is less than demand, random assignment is a fair method of allocating resources. Furthermore, the collective obligation among EU countries to implement programmes at this time should motivate member states to collaborate on the development of promising programmes worthy of implementation and evaluation. The precise nature of a model of the best programme is yet to be established. For adult sexual abusers of children in particular, no single programme has sufficient research credentials to distinguish it from others. Those charged with developing model programmes, however, should ensure that the model complies with the risk, need, and responsivity principles of effective correctional treatment. ${ }^{23} 24$ Furthermore, it would be valuable to conduct rigorous evaluations of drugs to reduce sex drive given promising results in preliminary studies and the prominence of such treatments in the debates concerning medical interventions for sexual abusers of children. ${ }^{36} 37$ 


\section{What is already known on this topic}

Previous systematic reviews found weak evidence for medical and psychological interventions in reducing reoffence in identified adult sexual offenders

No reviews have specifically examined effectiveness of interventions for adult and adolescent sexual abusers of children and those at higher risk of perpetrating such abuse (such as individuals with paedophilic sexual preference)

\section{What this study adds}

Despite high social importance, research on the effectiveness of individual level interventions for preventing sexual offending and reoffending against children remains inconclusive

There is insufficient evidence regarding benefits and risks of cognitive behavioural treatment for adults and adolescents who sexually abuse children and for children with sexual behaviour problems

There is weak evidence that multisystemic therapy prevents reoffending among adolescent sexual offenders

No studies meeting minimum quality standards were found for pharmacological treatments or for interventions directed towards individuals who had not sexually abused children but were at a higher risk of doing so

Contributors: SW, JL, RKH, and NL had the original idea and designed the study, interpreted results, and co-authored the paper. Together with PE and EML, they analysed results and drafted the manuscript. SW and JL managed data. SW is guarantor.

Funding: The Swedish Government, Department of Social Affairs commissioned the systematic review and funded some of the work. The funder had no influence on the process or conclusions of the present work. SW and JL were both employed by the Swedish Council on Health Technology Assessment (SBU). The views expressed are those of the authors and not necessarily those of Public Safety Canada or the Swedish Prison and Probation Administration.

Competing interests: All authors have completed the ICMJE uniform disclosure form at www.icmje.org/coi_disclosure.pdf (available on request from the corresponding author) and declare: no support from any organisation for the submitted work; no financial relationships with any organisations that might have an interest in the submitted work in the previous three years; no other relationships or activities that could appear to have influenced the submitted work.

Ethical approval: Not required.

Data sharing: No additional data available.

1 Pereda N, Guilera G, Forns M, Gomez-Benito J. The prevalence of child sexual abuse in community and student samples: a meta-analysis. Clin Psychol Rev 2009;29;328-38.

2 Stoltenborgh M, van lizendoorn MH, Euser EM, Bakermans-Kranenburg MJ. A global perspective on child sexual abuse: meta-analysis of prevalence around the world. Child Maltreat 2011;16;79-101.

3 Maniglio R. The impact of child sexual abuse on health: a systematic review of reviews. Clin Psychol Rev 2009;29;647-57.

4 Paras ML, Murad MH, Chen LP, Goranson EN, Sattler AL, Colbenson KM et al Sexual abuse and lifetime diagnosis of somatic disorders: a systematic review and meta-analysis. JAMA 2009:302:550-61.

5 Chen LP, Murad MH, Paras ML, Colbenson KM, Sattler AL, Goranson EN, et al. Sexual abuse and lifetime diagnosis of psychiatric disorders: systematic review and meta-analysis. Mayo Clin Proc 2010;85;618-29.

6 Hillberg T, Hamilton-Giachritsis C, Dixon L. Review of meta-analyses on the association between child sexual abuse and adult mental health difficulties: a systematic approach. Trauma Viol Abuse 2011;12;38-49.

7 Kendler KS, Bulik CM, Silberg J, Hettema JM, Myers J, Prescott CA. Childhood sexual abuse and adult psychiatric and substance use disorders in women: an epidemiological and cotwin control analysis. Arch Gen Psychiatry 2000;57;953-9.

8 Nelson EC, Heath AC, Madden PA, Cooper ML, Dinwiddie SH, Bucholz KK, et al. Association between self-reported childhood sexual abuse and adverse psychosocial outcomes: results from a twin study. Arch Gen Psychiatry 2002;59;139-45.

9 Jonas S, Bebbington P, McManus S, Meltzer H, Jenkins R, Kuipers E, et al. Sexual abuse and psychiatric disorder in England: results from the 2007 Adult Psychiatric Morbidity Survey. Psychol Med 2011;41;709-19.

10 Nelson EC, Heath AC, Lynskey MT, Bucholz KK, Madden PAF, Statham DJ, et al. Childhood sexual abuse and risks for licit and illicit drug-related outcomes: a twin study. Psychol Med 2006;36;1473-83.

11 Seto MC, Kjellgren C, Priebe G, Mossige S, Svedin CG, Långström N. Sexual victimization and sexually coercive behavior: a population study of Swedish and Norwegian male youth. Child Maltreat 2010;15;219-28.

12 Widom CP, Ames MA. Criminal consequences of childhood sexual victimization. Child Abuse Negl 1994:18;303-18.

13 Forsman M, Lảngström N. Child maltreatment and adult violent offending: population-based twin study addressing the "cycle of violence" hypothesis. Psychol Med 2012;42;1977-83.

14 Freyd JJ, Putnam FW, Lyon TD, Becker-Blease KA, Cheit RE, Siegel NB, et al. The science of child sexual abuse. Science 2005;308;501

15 Gilbert R, Widom CS, Browne K, Fergusson D, Webb E, Janson S. Burden and consequences of child maltreatment in high-income countries. Lancet 2009;373;68-81.

16 Krug EG, Dahlberg LL, Mercy JA, Zwi AB, Lozano R, eds. World report on violence and health. World Health Organization, 2002
17 Nagayama Hall GC. Sexual offender recidivism revisited: a meta-analysis of recen treatment studies. J Consult Clin Psychol 1995;63:802-9.

18 Gallagher A, Wilson DB, Hirschfield P, Coggeshall MB, MacKenzie DL. A quantitative review of the effects of sex offender treatment on sexual reoffending. Corrections Management Quarterly 1999;3;19-29.

19 White P, Bradley C, Ferriter M, Hatzipetrou L. Managements for people with disorders of sexual preference and for convicted sexual offenders. Cochrane Database Syst Rev 2000;2:CD000251

20 Hanson RK, Gordon A, Harris AJ, Marques JK, Murphy W, Quinsey VL, et al. First report of the collaborative outcome data project on the effectiveness of psychological treatment for sex offenders. Sex Abuse 2002;14:169-94.

21 Kenworthy T, Adams CE, Bilby C, Brooks-Gordon B, Fenton M. Psychological interventions for those who have sexually offended or are at risk of offending. Cochrane Database Syst Rev 2004;3;CD004858.

22 Lösel F, Schmucker M. The effectiveness of treatment for sexual offenders: comprehensive meta-analysis. J Exp Criminol 2005;1:117-46.

23 Hanson RK, Bourgon G, Helmus L, Hodgson S. The principles of effective correctional treatment also apply to sexual offenders: a meta-analysis. Crim Justice Behav 2009;36;865-91.

24 Andrews DA, Bonta J. The psychology of criminal conduct. 5th ed. LexisNexis Matthew Bender, 2010

25 Oxman $A D$, for the GRADE working group. Grading quality of evidence and strength of recommendations. BMJ 2004;328:1490.

26 Guyatt G, Oxman A, Vist G, Kunz R, Falck-Ytter Y, Alonso-Coello P, et al. GRADE: an emerging consensus on rating quality of evidence and strength of recommendations. $B M J$ 2008;336:924.

27 Medicinska och psykologiska metoder för att förebygga sexuella övergrepp mot barn. En systematisk litteraturöversikt. [Medical and psychological methods for preventing sexual offences against children. A systematic review.] Statens beredning för medicinsk utvärdering (SBU), 2011. www.sbu.se/sv/Publicerat/Gul/Sexuella-overgrepp-mot-barn- $/$.

28 Marques JK, Miederanders M, Day DM, Nelson C, van Ommeren A. Effects of a relapse prevention program on sexual recidivism: final results from California's sex offender treatment evaluation project (SOTEP). Sex Abuse 2005;17:79-107.

29 Marshall LE, Marshall WL, Fernandez YM, Malcolm PB, Moulden HM. The Rockwood Preparatory Program for sexual offenders: description and preliminary appraisal. Sex Abuse 2008;20;25-42.

30 McGrath R, Hoke S, Vojtisek J. Cognitive-behavioral treatment of sex offenders: a treatment comparison and long-term follow-up study. Crim Justice Behav 1998;25;203.

31 Procter E. A five year outcome evaluation of a community-based treatment programme for convicted sexual offenders run by the probation service. J Sex Aggression 1996;2;3-16.

32 Davidson PR. Behavioral treatment for incarcerated sex offenders: post-release outcome. A conference on sex offender assessment and treatment. Kingston, ON, Canada; 1984.

33 Borduin $\mathrm{CM}$, Schaeffer $\mathrm{CM}$, Heiblum N. A randomized clinical trial of multisystemic therapy with juvenile sexual offenders: effects on youth social ecology and criminal activity. $J$ Consult Clin Psychol 2009;77;26-37.

34 Worling JR, Litteljohn A, Bookalam D. 20-year prospective follow-up study of specialized treatment for adolescents who offended sexually. Behav Sci Law 2010;28;46-57.

35 Carpentier MY, Silovsky JF, Chaffin M. Randomized trial of treatment for children with sexual behavior problems: ten-year follow-up. J Consult Clin Psychol 2006;74:482-8.

36 Bhaumik S. Indian medical experts shun chemical castration for rapists. BMJ 2013;346:f64.

37 Grubin D, Beech A. Chemical castration for sex offenders: doctors should avoid becoming agents of social control. BMJ 2010;340:c74.

38 Curtis NM, Ronan KR, Borduin CM. Multisystemic treatment: a meta-analysis of outcome studies. J Fam Psych 2004;18:411-9.

39 Littell JH, Popa M, Forsythe, B. Multisystemic therapy for social, emotional, and behaviora problems in youth aged 10-17. Campbell Systematic Reviews, 2005.

40 National Institute for Health and Care Excellence (NICE). Antisocial behaviour and conduct disorders in children and young people. No 158. NICE, 2013. http://guidance.nice.org.uk/ CG158.

41 Lovins B, Lowenkamp CT, Latessa EJ. Applying the risk principle to sex offenders: Can treatment make some sex offenders worse? Prison Journal 2009;89;344-57.

42 Beier KM, Neutze J, Mundt, IA, Ahlers CJ, Goecker D, Konrad A, et al. Encouraging self-identified pedophiles and hebephiles to seek professional help: first results of the Prevention Project Dunkelfeld (PPD). Child Abuse Negl 2009;33;545-9.

43 Juni $\mathrm{P}$, Witschi A, Bloch R, Egger M. The hazards of scoring the quality of clinical trials or meta-analysis. JAMA 1999;282:1054-60.

44 Dennis JA, Khan O, Ferriter M, Huband N, Powney MJ, Duggan C. Psychological interventions for adults who have sexually offended or are at risk of offending. Cochrane Library, John Wiley, 2012.

45 Hanson RK, Bussière MT. Predicting relapse: a meta-analysis of sexual offender recidivism studies. J Consult Clin Psychol 1998;66;348-62. 
46 European Union Convention on the Protection of Children against Sexual Exploitation and Sexual Abuse. Council of Europe. Treaty Series No 201. 2007. http://conventions. coe.int/Treaty/Commun/QueVoulezVous.asp?NT=201\&CL=ENG.

Accepted: 15 July 2013
Cite this as: BMJ 2013;347:f4630

This is an Open Access article distributed in accordance with the Creative Commons Attribution Non Commercial (CC BY-NC 3.0) license, which permits others to distribute, remix, adapt, build upon this work non-commercially, and license their derivative works on different terms, provided the original work is properly cited and the use is non-commercial. See: http://creativecommons.org/licenses/by-nc/3.0/. 


\section{Tables}

Table 1/ Characteristics of individual studies included in systematic review of offender oriented interventions aimed at reducing sexual offending and reoffending against children

\begin{tabular}{|c|c|c|c|c|c|c|c|c|}
\hline & \multirow{2}{*}{$\begin{array}{l}\text { Study } \\
\text { design }\end{array}$} & \multirow{2}{*}{$\begin{array}{l}\text { Estimated } \\
\text { baseline risk of } \\
\text { reoffending }\end{array}$} & \multirow[b]{2}{*}{ Setting } & \multirow{2}{*}{$\begin{array}{l}\text { Intervention/ } \\
\text { comparison } \\
\text { condition }\end{array}$} & \multirow{2}{*}{$\begin{array}{c}\text { Years of } \\
\text { follow-up } \\
\text { (range) }\end{array}$} & \multicolumn{2}{|c|}{ Reoffenders/total No in group } & \multirow{2}{*}{$\begin{array}{l}\text { Estimated } \\
\text { overall risk of } \\
\text { bias }\end{array}$} \\
\hline & & & & & & Intervention & Control & \\
\hline \multicolumn{9}{|l|}{ Convicted adults } \\
\hline Marques, $2005^{28}$ & $\mathrm{RCT}$ & Moderate & Prison & CBT/NT & $(5-14)$ & $57 / 259$ & $45 / 225$ & Low \\
\hline Marshall, $2008^{29}$ & OBS & Lower & $\begin{array}{l}\text { Correctional } \\
\text { centre }\end{array}$ & CBT-MI/UNS & $3(0.3-7)$ & $1 / 94$ & $4 / 86$ & Moderate \\
\hline McGrath, $1998^{30}$ & OBS & Lower & $\begin{array}{l}\text { Probation } \\
\text { services }\end{array}$ & CBT-RP/UNT & 5 & $1 / 71$ & $5 / 32$ & Moderate \\
\hline Procter, $1996^{31}$ & OBS & Lower & $\begin{array}{l}\text { Probation } \\
\text { services }\end{array}$ & CBT/SPS & 4.5 & $2 / 39$ & $2 / 40$ & Moderate \\
\hline Davidson, $1984^{32}$ & OBS & Higher & Prison & $\mathrm{BEH} / \mathrm{NT}$ & 5 & $7 / 57$ & $16 / 57$ & Moderate \\
\hline \multicolumn{9}{|l|}{ Adolescents } \\
\hline Borduin, $2009^{33}$ & RCT & Moderate & Community & MST/UCS-CBT & 9 & $2 / 24$ & $11 / 24$ & Moderate \\
\hline Worling, $2010^{34}$ & OBS & Moderate & Community & CBT/FAM & 16 & $5 / 58$ & $19 / 90$ & Moderate \\
\hline \multicolumn{9}{|c|}{ Children with SBP } \\
\hline Carpentier, $2006^{35}$ & $\mathrm{RCT}$ & - & Community & CBT-PS/GPT-PS & 11 & $1 / 64$ & $7 / 71$ & Low \\
\hline
\end{tabular}

$\mathrm{RCT}=$ randomised controlled trial, $\mathrm{OBS}=$ observational study, $\mathrm{CBT}=$ cognitive behavioural therapy, $\mathrm{SBP}=$ sexual behaviour problems, $\mathrm{NT}=\mathrm{no}$ treatment, $\mathrm{BEH}=\mathrm{behaviour}$ therapy, MI=motivational interviewing, UNT=unspecified treatment (not specialised), UNS=unspecified sexual offender treatment, RP=relapse prevention, $\mathrm{SPS}=$ standard probation supervision, MST=multisystemic therapy, UCS=usual community services, FAM=family therapy, PS=parental support, GPT=group play therapy. 
Table 2/ Characteristics of treatment provided in individual studies included in systematic review of offender oriented interventions aimed at reducing sexual offending and reoffending against children

\begin{tabular}{llcc} 
& & \multicolumn{2}{c}{ Intervention } \\
\cline { 3 - 4 } Affiliation & Population & Treatment & Control
\end{tabular}

\section{Convicted adults}

Marques, Marques involved in Incarcerated male sexual offenders. SOTEP (Sex Offender Treatment and Evaluation No treatment specified. No $2005^{28} \quad$ setting up treatment $704 / 1407$ eligible men with $\leq 2$ convictions Project). Cognitive behavioural therapy (CBT) based dropouts programme, Nelson before index offence, admitted to response prevention model, 90 min group sessions was clinical director. committing sexual offence, $I Q>80$, and had each week, response-prevention. Specialised Other authors were not presented severe management groups on sex education, human sexuality, members of problems in prison. $78 \%$ child abusers, relaxation training, stress and anger management, evaluation team $\quad 18.4 \%$ prior convictions of sexual crimes. and social skills. Class to prepare for life in society employed by Medium risk for reoffending programme sponsor after release, 2 year treatment programme, 1 year aftercare programme. Dropout rate $21 \%(55 / 259)$ Marshall, Authors involved in 94 incarcerated adult male sexual offenders Rockwood Preparatory Programme for Sexual No preparatory programme, $2008^{29}$ either setting up and with relatively low risk of reoffending. delivering programme, Clients had completed Rockwood or in managing Preparatory Programme for Sexual treatment site Offenders, 73 were child abusers Offenders: 6-8 weeks, two $2.5 \mathrm{~h}$ group sessions/week, and then full sexual offender treatment programme. Length: $2.5 \mathrm{~h} /$ week, CBT not specified. Dropout rate not and motivational interviewing (MI) approach, such reported as victim empathy exercises. Dropout rate not reported

McGrath, Not reported, but 103 of 122 adult male sex offenders $1998^{30} \quad$ McGrath has been comprising $98.4 \%$ of all convicted sex Specialised treatment: CBT, relapse prevention Non-specialised treatment. model. Included accepting responsibility, modifying Diverse treatment methods. clinical director of this offenders placed on community correctional cognitive distortions, developing victim empathy, Length was few months to $>6$ program, possibly supervision for $>3$ months in $1984-5$ in rural controlling sexual arousal, improving social years. Of $n=32,1 \mathrm{dropout}$ during time period Vermont. 91 of $122(74.6 \%)$ were child evaluated abusers. Treatment $(\mathrm{n}=71)$ and contro $(n=32)$ individuals agreed to enrol in treatment. No treatment group $(n=19)$ excluded as inherently biased (mainly refusers). Offenders had low risk of reoffending

Procter, Not reported 54 convicted adult male sex offenders with CBT, 10 group sessions 6 h/day over 2 weeks, and Standard probation $1996^{31}$ low risk for reoffending. All sex offenders 14 supervision sessions during 6 months. Themes supervision. No dropouts who commenced treatment with Cherwell covered: taking responsibility, awareness of victim Group 1989-92. 39 were child abusers perspectives, challenging distorted perceptions, strategies to interrupt behaviour patterns, increase disclosure about offences, sexual behaviour, and sexual fantasy. No dropouts

Davidson, Not reported $1984^{32}$
101 incarcerated male sexual offenders with high risk of reoffending. All men who were treated in sex offender treatment programme at Canadian penitentiary 1974-92. 57 were paedophiles or hebephiles

Behavioural intervention. Training in interpersonal No treatment. Dropout rate not

behaviour, sex education, temper control, changing reported physiological responses to inappropriate sexual stimuli. Individual psychotherapy. 4 months in group therapy. Dropout rate not reported

\section{Adolescents}

Borduin, Borduin involved in 51 eligible young people arrested for $2009^{33}$ serious sexual offence, currently living with treatment programme at least one parent figure, and with no evidence of psychosis or serious mental retardation, 48 consented to participate in study. Mean age 14.0 (SD 1.9). Mean number of previous sexual offences: 1.62 Medium risk of sexual reoffence

Worling, Not reported, although Adolescents convicted of or who $2010^{34} \quad$ Worling is author and acknowledged sexual offence. None were possibly developer of below borderline intellectual functioning programme manual Mean age 15.5 (SD 1.5, range 12-19). Medium risk of sexual reoffence
Multisystemic therapy (MST). Community and family Usual community services based, ecological model, including treatment at complemented with CBT group home. Empowering parents and adolescents; deal treatment, 90 minutes twice with denial about offences, safety planning, improving relations with prosocial peers. Mean 60-90 minutes once/week. length 30.8 (SD 12.3) weeks. No dropouts Length: mean 30.1 (SD 18.0) weeks. Of $n=24,2$ dropouts

Sexual Abuse: Family Education and Treatment Only assessment, 67\% (SAFE-T) Programme. Assessment and treatment received treatment elsewhere $\mathrm{CBT}$ intervention with family focus. Included increasing insight, developing offence prevention unknown plans, enhancing awareness of victim impact, and social relationships, and reducing impact of traumatic events. $71 \%$ of treatment group participated in both group and family therapy in addition to individual therapy. Mean length 24.4 (SD 10.7) months. Of $n=58,18$ dropouts after 12 months. Early dropouts (before 12 months, $n=27$ ) transferred to control group 
Table 2 (continued)

\begin{tabular}{|c|c|c|c|}
\hline \multirow[b]{2}{*}{ Affiliation } & \multirow[b]{2}{*}{ Population } & \multicolumn{2}{|l|}{ Intervention } \\
\hline & & Treatment & Control \\
\hline \multicolumn{4}{|l|}{ Children with SBP } \\
\hline $\begin{array}{l}\text { Carpentier, Not reported } \\
2006^{35}\end{array}$ & $\begin{array}{l}\text { Children with clinically relevant sexual } \\
\text { problem behaviour, age 5-12 with normal } \\
\text { intellectual capacity. Children and their } \\
\text { families recruited from child welfare, law } \\
\text { enforcement, juvenile court, physicians, } \\
\text { school personnel, mental health centres }\end{array}$ & $\begin{array}{l}\text { CBT, manualised } 12 \text { session, group based therapy. } \\
\text { Child groups: behaviour modification, } \\
\text { psychoeducation, identifying inappropriate sexual } \\
\text { behaviour, learning behaviour rules, self control, } \\
\text { sex education. Parent groups: information on } \\
\text { normal/atypical childhood sexual behaviour, child } \\
\text { management skills. Dropout rate not reported }\end{array}$ & $\begin{array}{l}\text { Client centred and } \\
\text { psychodynamic group play } \\
\text { therapy. Less structured, } \\
\text { manualised, } 12 \text { sessions. } \\
\text { Children: drawing self outlines, } \\
\text { play materials, minimal } \\
\text { direction from therapists who } \\
\text { gave reflections and } \\
\text { interpreted patterns of play. } \\
\text { Parent groups: themes similar } \\
\text { to CBT-groups, presented in } \\
\text { less directive manner. Dropout } \\
\text { rate not reported }\end{array}$ \\
\hline
\end{tabular}


Table 3| GRADE based summary of evidence from systematic review of offender oriented interventions aimed at reducing sexual (re)offending against children

\section{No of participants Relative risk $(95 \% \mathrm{Cl})$ Event rate in control group Quality of evidence}

Effects of cognitive behavioural therapy (CBT) with or without relapse prevention among adult sex offenders against children

Sexual reoffence, moderate risk offenders, 5-14 year follow-up:

\begin{tabular}{|c|c|c|c|c|}
\hline Marques $2005^{28}(\mathrm{RCT})$ & 484 & $1.10(0.78$ to 1.56$)$ & $20 \%$ & Insufficient \\
\hline \multicolumn{5}{|c|}{ Sexual reoffence, lower risk offenders, 3-5 year follow-up: } \\
\hline Marshall $2008^{29}(\mathrm{OBS})$ & \multirow[t]{3}{*}{362} & $0.23(0.03$ to 2.01$)$ & $5 \%$ & \multirow[t]{3}{*}{ Insufficient } \\
\hline McGrath $1998^{30}$ (OBS) & & 0.09 (0.01 to 0.74$)$ & $16 \%$ & \\
\hline Procter $1996^{31}$ (OBS) & & $1.03(0.15$ to 6.92$)$ & $5 \%$ & \\
\hline \multicolumn{5}{|c|}{ Sexual reoffence, higher risk offenders, 5 year follow-up: } \\
\hline Davidson $1984^{32}$ (OBS) & 114 & $0.44(0.19$ to 0.98$)$ & $28 \%$ & Insufficient \\
\hline \multicolumn{5}{|c|}{ Effects of multisystemic therapy (MST) and cognitive behavioural therapy (CBT) in adolescent sexual offenders } \\
\hline \multicolumn{5}{|c|}{ Sexual reoffence, moderate risk offenders, 9 year follow-up: } \\
\hline Borduin $2009^{33}(\mathrm{RCT})$ & 48 & $0.18(0.04$ to 0.73$)$ & $46 \%$ & Weak \\
\hline \multicolumn{5}{|c|}{ Sexual reoffence, moderate risk offenders, 16 year follow-up: } \\
\hline Worling $2010^{34}$ (OBS) & 148 & $0.41(0.16$ to 1.03$)$ & $21 \%$ & Insufficient \\
\hline
\end{tabular}

Effect of cognitive behavioural therapy (CBT) in children with sexual behavioural problems (SBP) directed against other children Sexual offence 10 year follow-up:

\begin{tabular}{lllll}
\hline Carpentier $2006^{35}(\mathrm{RCT})$ & 135 & $0.16(0.02$ to 1.25$)$ & $10 \%$ & Insufficient \\
\hline
\end{tabular}

$\mathrm{RCT}=$ randomised controlled trial, OBS=observational study. 


\section{Figure}

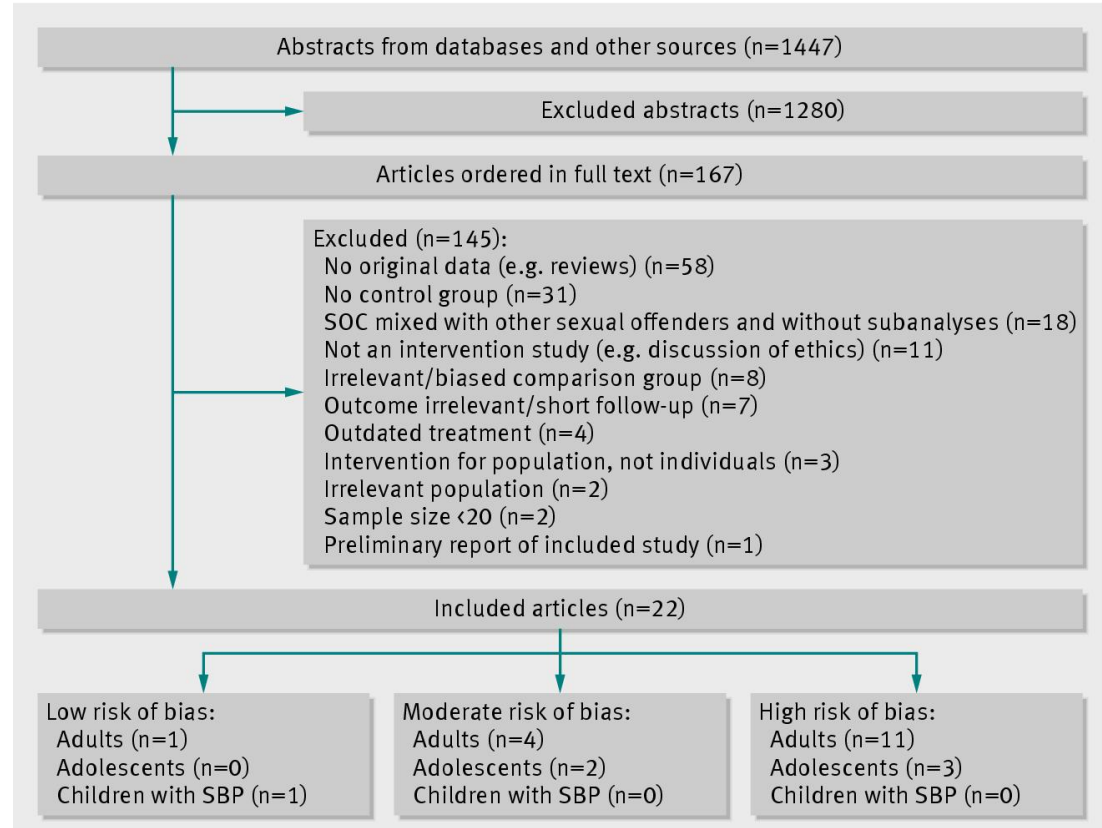

Results of literature search and selection and assessment of primary studies with adult and adolescent sexual abusers of children and children with sexual behaviour problems (SBP) 